\title{
Mutagenicity of New Lead Compounds to Treat Sickle Cell Disease Symptoms in a Salmonella/Microsome Assay
}

\section{Jean Leandro dos Santos ${ }^{1{ }^{*},}$, Eliana A. Varanda $^{2}$, Lídia Moreira Lima ${ }^{3}$ and Chung Man Chin ${ }^{1}$}

1 Lapdesf-Laboratório de Pesquisa e Desenvolvimento de Fármacos, Departamento de Fármacos e Medicamentos, Faculdade de Ciências Farmacêuticas, Univ Estadual Paulista-UNESP, Rodovia Araraquara Jaú Km. 01, 14801-902, Araraquara, SP, Brazil

2 Departamento de Ciências Biológicas, Faculdade de Ciências Farmacêuticas, Univ Estadual Paulista-UNESP, Rodovia Araraquara Jaú Km. 01, 14801-902, Araraquara, SP, Brazil

3 LASSBio-Laboratório de Avaliação e Síntese de Substâncias Bioativas, Faculdade de Farmácia, Univ Federal do Rio de Janeiro-UFRJ, Centro de Ciências da Saúde, Cidade Universitária, Ilha do Fundão, 21.944-190-Rio de Janeiro, RJ, Brazil

* Author to whom correspondence should be addressed; E-Mail: santosj1@fcfar.unesp.br; Tel.: +55-16-3301-6972; Fax: +55-16-3301-6960.

Received: 15 January 2010 / Accepted: 10 February 2010 / Published: 25 February 2010

\begin{abstract}
A series of phthalimide derivatives planned as drugs candidates to treat the symptoms of sickle cell anemia were evaluated in a mutagenicity test using strains of Salmonella typhimurium TA100 and TA102, without and with addition of S9 mixture, with the aim to identify the best structural requirements for a drug candidate without genotoxic activity. The compounds (1,3-dioxo-1,3-dihydro-2 $H$-isoindol-2-yl)methyl nitrate (1); (1,3-dioxo-1,3-dihydro- $2 \mathrm{H}$-isoindol-2-yl)ethyl nitrate (2); 3-(1,3-dioxo-1,3-dihydro-2Hiso-indol-2-yl)benzyl nitrate (3); 4-(1,3-dioxo-1,3-dihydro- $2 H$-isoindol-2-yl)- $N$-hydroxybenzenesulfonamide (4); 4-(1,3-dioxo-1,3-dihydro-2H-isoindol-2-yl)benzyl nitrate (5) and 2-[4-(1,3-dioxo-1,3-dihydro-2H-isoindol-2-yl)phenyl]ethyl nitrate (6) presented mutagenic potency ranging between $0-4,803$ revertants/ $\mu$ mol. These results allowed us to propose that a methyl spacer linked to a nitrate ester subunit associated to meta aromatic substitution decreases mutagenicity.
\end{abstract}

Keywords: AMES test; mutagenicity; sickle cell; phthalimide derivatives 


\section{Introduction}

Sickle cell disease is a hematological genetic disease that results from a single point mutation of $\beta$ Glu6 in $\mathrm{Hb}$ to $\beta \mathrm{Val} 6$ in $\mathrm{HbS}$. In the deoxygenated state there is an interaction between the mutation region of one $\mathrm{HbS}$ molecule and a region defined by $\beta$ Phe 85 and $\beta$ Leu88 in the heme pocket of another HbS. This interaction leads to polymerization that causes the normally flexible red blood cells (RBC) to adopt rigid, sickle like shapes that block small capillaries initiating the vaso-oclusive process, and causing local tissue damage and severe pain $[1,2]$.

Hydroxyurea (HU) has been utilized for at least two decades in the treatment of sickle cell disease. The beneficial effect of HU has been associated with its capacity to induce fetal hemoglobin synthesis. Fetal hemoglobin ( $\mathrm{HbF}$ ) is predominant during fetal life and presents greater affinity for oxygen that normal hemoglobin. HbF concentration decreases after birth but there is an association between increasing this kind of hemoglobin with reduction of painful episodes in patients with sickle cell disease [3]. Besides, HU is metabolized to nitric oxide that has an important role in the vaso-oclusive process. HU is known as a ribonucleotide reductase inhibitor and as an antineoplasic drug that provokes DNA alterations (genotoxic activity), inducing gene and chromosome mutations [4,5].

As a result, the introduction of new drugs with the same beneficial effect for treatment of the sickle cell disease without genotoxic activity is necessary and urgent. Exploring the ability of HU, as a NO-source, we have designed the compounds (1,3-dioxo-1,3-dihydro- $H$-isoindol-2-yl)methyl nitrate (1); (1,3-dioxo-1,3-dihydro-2 $H$-isoindol-2-yl)ethyl nitrate (2); 3-(1,3-dioxo-1,3-dihydro- $H$-isoindol2-yl)-benzyl nitrate (3); 4-(1,3-dioxo-1,3-dihydro- $2 \mathrm{H}$-isoindol-2-yl)- $\mathrm{N}$-hydroxybenzenesulfonamide (4); 4-(1,3-dioxo-1,3-dihydro-2H-isoindol-2-yl)benzyl nitrate (5) and 2-[4-(1,3-dioxo-1,3-dihydro-2Hiso-indol-2-yl)phenyl]ethyl nitrate (6) as potential NO-donors. These compounds 1-6 have presented an analgesic and anti-inflammatory profile and the capacity to stimulate the gamma globin RNAm synthesis using K562 cells [6].

The generation of reactive species could be responsible for a mutagenic activity of several compounds with NO-donor properties. It has been reported that the capacity to generate nitric oxide by some compounds in the AMES test is responsible for observed mutagenic activity due to nitrosation of amines by NOx [7,8]. The nitric oxide induces mutations in Salmonella typhimurium strains used in the AMES test and can damage the DNA and lead to mutations of the DNA base sequence [9].

In vitro mutagenicity studies are an important part of discovery activities and are frequently critical in determining the future of a drug candidate. A drug candidate that is active in a mutagenicity test or that produce mutagenic metabolites by activation in a microsomal enzyme system generally will be discarded in favor of a backup candidate [10].

The objective of this study was to evaluate which compounds presented mutagenic activity in the AMES assay and to trace the structure-mutagenicity relationship profile in order to identify potentially hazardous phthalimide drug candidates. Genetic toxicology testing in drug discovery and optimization serve to quickly identify mutagens and remove them from development. In this work, the mutagenicity activities of compounds were evaluated in AMES tester Salmonella typhimurium strains TA100 and TA102 that are capable of detecting mutations that cause substitution of base pairs. Results from genetic toxicology tests, in combination with an adequate pharmacology profile are used as the basis to approve clinical trials of drug candidates. 


\section{Results and Discussion}

Table 1 shows the number of revertants/plate, the standard deviation and the mutagenic index (MI) after the treatments with the compounds, in the two different strains of Salmonella typhimurium, with

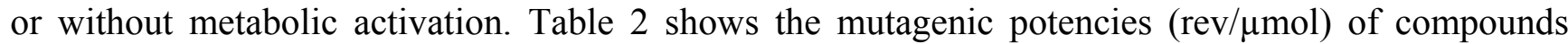
observed using Salmonella typhimurium TA100 and TA102 in presence (+S9) and absence (-S9) of metabolic activation.

Table 1. Mutagenic activity expressed as the mean and standard deviation of the number of revertants/plate in bacterial strains TA100 and TA102 exposed to compounds (1-6) and $\mathrm{HU}$, at various doses, with (+S9) or without (-S9) metabolic activation.

\begin{tabular}{|c|c|c|c|c|c|}
\hline \multirow{3}{*}{ Compounds } & \multirow{3}{*}{$\begin{array}{c}\text { Concentration } \\
\mu \mathrm{mol} / \mathrm{plate}\end{array}$} & \multicolumn{4}{|c|}{ Revertants/plate in Salmonella typhimurium strains } \\
\hline & & \multicolumn{2}{|c|}{ TA100 } & \multicolumn{2}{|c|}{ TA102 } \\
\hline & & +S9 & -S9 & +S9 & -S9 \\
\hline \multirow{7}{*}{$\begin{array}{r}\mathrm{H}_{2} \mathrm{~N}_{\mathrm{H}}^{\mathrm{N}^{-}} \\
\mathbf{H U} \\
\mathbf{H U}\end{array}$} & 0 & $129.3 \pm 8.1$ & $143 \pm 4.8$ & $372.3 \pm 20.5$ & $370 \pm 17.2$ \\
\hline & 29.25 & $178.33 \pm 15.1 *(1.4)$ & $149 \pm 8.9(1.0)$ & $399 \pm 31(1.1)$ & $411.3 \pm 9.8(1.1)$ \\
\hline & 58.5 & $240 \pm 3 * *(1.8)$ & $159 \pm 11(1.1)$ & $484.6 \pm 36(1.3)$ & $498 \pm 15.3(1.3)$ \\
\hline & 117 & $220.7 \pm 17.8 * *(1.7)$ & $268.7 \pm 13.5^{*}(1.9)$ & $563.3 \pm 22 * *$ & $602 \pm 8.7 *(1.6)$ \\
\hline & & & & $(1.5)$ & \\
\hline & 234 & $276 \pm 27.7 * *(2.1)$ & $345 \pm 21.2 * *(2.4)$ & $\begin{array}{c}764.3 \pm 20^{* *} \\
(2.0)\end{array}$ & $799.6 \pm 12 * *(2.2)$ \\
\hline & 468 & $315.3 \pm 16.1 * *(2.4)$ & $358.6 \pm 5.5^{* *}(2.5)$ & $593 \pm 23 * *(1.6)$ & $550 \pm 7.5 * *(1.5)$ \\
\hline \multirow{7}{*}{ (1) } & 0 & $129.3 \pm 8.1$ & $136.7 \pm 2.4$ & $213.5 \pm 15.5$ & $197.33 \pm 16.01$ \\
\hline & 0.007 & $126.3 \pm 8.1(1.0)$ & $140.5 \pm 17(1.0)$ & $288 \pm 11.3(1.3)$ & $249.7 \pm 12(1.2)$ \\
\hline & 0.014 & $133.3 \pm 11(1.0)$ & $161.7 \pm 11(1.2)$ & $320.8 \pm 17 *(1.5)$ & $263.7 \pm 15(1.3)$ \\
\hline & 0.028 & $140.3 \pm 2(1.1)$ & $192.7 \pm 3.06(1.4)$ & $385 \pm 21.8^{* *}$ & $261.3 \pm 20(1.3)$ \\
\hline & & & & $(1.8)$ & \\
\hline & 0.056 & $154 \pm 14.2(1.2)$ & $234 \pm 39.5^{* *}(1.7)$ & $499 \pm 8.9 * *(2.3)$ & $153 \pm 21(0.8)$ \\
\hline & 0.112 & $155 \pm 5.9(1.2)$ & $335 \pm 15.7 * *(2.4)$ & $351.2 \pm 12 *(1.6)$ & $141 \pm 18(0.7)$ \\
\hline \multirow{6}{*}{ (2) } & 0 & $104 \pm 7.4$ & $115 \pm 13.2$ & $219 \pm 8.9$ & $323 \pm 10.2$ \\
\hline & 0.01 & $335 \pm 10.8 * *(3.2)$ & $171 \pm 38.9 *(1.5)$ & $249 \pm 11.7(1.1)$ & $394 \pm 30(1.2)$ \\
\hline & 0.021 & $354 \pm 6.9 * *(3.4)$ & $200 \pm 13.3 *(1.7)$ & $269 \pm 10.6(1.2)$ & $411 \pm 24(1.3)$ \\
\hline & 0.042 & $397 \pm 25.9^{* *}(3.8)$ & $223 \pm 15.04 *(1.9)$ & $239 \pm 22.5(1.1)$ & $452 \pm 35.4(1.4)$ \\
\hline & 0.085 & $416 \pm 15.2 * *(4.0)$ & $226 \pm 20.2 *(2.0)$ & $247 \pm 21.4(1.1)$ & $468 \pm 23(1.4)$ \\
\hline & 0.170 & $261 \pm 11 * *(2.5)$ & $165 \pm 11.1 *(1.4)$ & $205 \pm 32(0.9)$ & $518 \pm 14^{* *}(1.6)$ \\
\hline \multirow{6}{*}{ (3) } & 0 & $129 \pm 8.1$ & $179 \pm 8.72$ & $222 \pm 12.5$ & $254.7 \pm 14.6$ \\
\hline & 0.224 & $146 \pm 5(1.1)$ & $216.7 \pm 10.2(1.2)$ & $272 \pm 26(1.2)$ & $281 \pm 25(1.1)$ \\
\hline & 0.488 & $153 \pm 13.1(1.2)$ & $234.5 \pm 24.6(1.3)$ & $378 \pm 6.1 *(1.7)$ & $286 \pm 4.2(1.1)$ \\
\hline & 0.896 & $163 \pm 9.3(1.2)$ & $266.3 \pm 8.4^{*}(1.5)$ & $399.3 \pm 12 *(1.8)$ & $303 \pm 9.2(1.2)$ \\
\hline & 1.8 & $165 \pm 12.5(1.3)$ & $294.5 \pm 5.3 *(1.6)$ & $405 \pm 11 *(1.8)$ & $395.7 \pm 9 * *(1.5)$ \\
\hline & 3.58 & $155 \pm 8.2(1.3)$ & $323.7 \pm 10.2 *(1.8)$ & $431 \pm 17.9 *(1.9)$ & $410.3 \pm 9.7 *(1.6)$ \\
\hline
\end{tabular}


Table 1. Cont.

\begin{tabular}{|c|c|c|c|c|c|}
\hline & 0 & $129.3 \pm 8.14$ & $126.7 \pm 12.1$ & $312.3 \pm 27.5$ & $197.3 \pm 16.1$ \\
\hline & 0.98 & $160 \pm 12.4(1.2)$ & $146.3 \pm 5.1(1.1)$ & $323 \pm 5.54(1.0)$ & $222 \pm 12(1.1)$ \\
\hline & 1.96 & $175.7 \pm 2(1.4)$ & $172.7 \pm 7.8(1.4)$ & $385 \pm 33.1(1.2)$ & $241 \pm 13(1.2)$ \\
\hline (4) & 3.92 & $194.2 \pm 15(1.5)$ & $190 \pm 11.3 *(1.5)$ & $423.7 \pm 22(1.3)$ & $251 \pm 19.2(1.3)$ \\
\hline & 7.85 & $206 \pm 13.6^{* *}(1.6)$ & $208 \pm 12.5^{*}(1.6)$ & $443 \pm 14.4(1.4)$ & $232 \pm 13.1(1.2)$ \\
\hline & 15.7 & $354 \pm 6.5 *(2.7)$ & $155 \pm 2.8(1.22)$ & $295 \pm 4.9(0.9)$ & $210 \pm 17(1.1)$ \\
\hline & 0 & $129.3 \pm 8.1$ & $179 \pm 8.7$ & $372.3 \pm 27.5$ & $260.1 \pm 11.6$ \\
\hline & 0.224 & $157 \pm 13(1.2)$ & $220 \pm 18(1.2)$ & $385.7 \pm 13(1.0)$ & $340.3 \pm 9.7(1.3)$ \\
\hline & 0.488 & $184.7 \pm 16^{*}(1.4)$ & $239 \pm 11.5(1.3)$ & $427.3 \pm 5(1.1)$ & $373.5 \pm 21(1.4)$ \\
\hline$(5)$ & 0.896 & $192.7 \pm 16^{*}(1.5)$ & $261 \pm 10.2(1.4)$ & $436.7 \pm 21(1.2)$ & $391.2 \pm 6.3 *(1.5)$ \\
\hline & 1.8 & $216.7 \pm 18 * *(1.7)$ & $303,8 \pm 17 *(1.7)$ & $390.3 \pm 9.3(1.0)$ & $486.8 \pm 20^{* *}(1.9)$ \\
\hline & 3.58 & $263 \pm 12.3 * *(2.0)$ & $349 \pm 5.6^{* *}(1.9)$ & $350 \pm 6(0.9)$ & $420 \pm 8.6^{*}(1.6)$ \\
\hline & 0 & $129.3 \pm 8.1$ & $116.7 \pm 12.4$ & $295.3 \pm 28$ & $197.3 \pm 16.1$ \\
\hline & 0.12 & $363 \pm 25.2 * *(2.8)$ & $121.5 \pm 14(1.0)$ & $335.3 \pm 11(1.1)$ & $245 \pm 6.9(1.2)$ \\
\hline & 0.25 & $478.7 \pm 4.22 * *(3.7)$ & $135.3 \pm 12(1.1)$ & $372.3 \pm 27.5(1.3)$ & $262 \pm 19.1(1.3)$ \\
\hline (6) & 0.5 & $628 \pm 40.8^{* *}(4.9)$ & $138.3 \pm 13(1.2)$ & $406 \pm 14.1(1.4)$ & $286.7 \pm 18(1.4)$ \\
\hline & 1 & $739 \pm 25.4 * *(5.7)$ & $153.3 \pm 5(1.3)$ & $465 \pm 10.6^{*}(1.6)$ & $305.7 \pm 10^{*}(1.5)$ \\
\hline & 2 & $750 \pm 13.6^{* *}(5.8)$ & $177 \pm 23.6^{*}(1.5)$ & $447 \pm 19.8 *(1.5)$ & $201 \pm 4.7(1.0)$ \\
\hline Positive control*** & - & $2545 \pm 73.6$ & $2231 \pm 66.9$ & $812 \pm 26.1$ & $881 \pm 56.1$ \\
\hline
\end{tabular}

$0=$ negative control (DMSO-100 $\mu \mathrm{L} /$ plate) $* P<0.01$ or $* * \mathrm{P}<0.05$ (ANOVA). The values in parenthesis $=$ mutagenic index. Numbers represent averages of triplicates from the three different experiments \pm the standard deviation. ${ }^{* * *}$ Positive control: sodium azide $(1.25 \mu \mathrm{g} /$ plate) for TA100 (-S9), daunomycin (3 $\mu \mathrm{g} / \mathrm{plate})$ for TA102 (-S9) and 2-anthramine (1.25 $\mu \mathrm{g} / \mathrm{plate})$ for TA100 (+S9) and 2-aminofluorene $(1.25 \mu \mathrm{g} /$ plate $)$ for TA102 $(+\mathrm{S} 9)$.

Table 2. Mutagenic potencies (rev/ $\mu \mathrm{mol}$ ) observed for HU and compounds (1-6) with positive mutagenicity $(\mathrm{MI} \geq 2)$ in TA100 and TA102 Salmonella typhimurium strains in presence (+S9) and absence (-S9) of metabolic activation.

\begin{tabular}{cccccc}
\hline Compounds & TA100 & & \multicolumn{2}{c}{ TA102 } \\
& (+S9) & (-S9) & (+S9) & (-S9) \\
\hline HU & 1.8 & 1.1 & 1.7 & 2.0 \\
1 & - & 1795 & 4803 & - \\
2 & 1041 & 4025 & - & - \\
3 & - & - & - & - \\
4 & 13.6 & - & - & - \\
5 & 31 & - & - & - \\
6 & 1393 & - & - & - \\
\hline
\end{tabular}

Compounds 1-6 were designed using hybridization as a molecular modification strategy and they were selected based on reports about tumor necrosis factor alpha inhibition and considering structure- 
activity relationships of phthalimide derivatives [6]. Compounds $\mathbf{1 , 2}, \mathbf{3}, \mathbf{5}$ and $\mathbf{6}$ are nitrate organic ester derivatives and the compound $\mathbf{4}$ is a sulphonylhydroxamic acid derivative.

HU exhibited mutagenicity in strains TA100 and TA102, in the presence and the absence of metabolic activation. In TA102 strain, the concentration of $468 \mu \mathrm{mol} /$ plate induced a reduction in number of revertants, consequence of the toxicity caused by HU. The mutagenicity was observed at $234 \mu \mathrm{mol} /$ plate with mutagenic index of 2.0 and 2.2 in presence and absence of metabolic activation, respectively (Table 1). The mutagenic potency were 1.7 revertants $/ \mu \mathrm{mol}(+\mathrm{S} 9)$ and 2.0 revertants/ $\mu$ mol (-S9) to TA102 strain (Table 2). Using TA100, mutagenic index higher than 2 was observed at concentrations above $234 \mu \mathrm{mol} /$ plate. The mutagenic potency was 1.8 revertants/ $\mu \mathrm{mol}$ and 1.1 revertants $/ \mu \mathrm{mol}$ in the presence and absence of metabolic activation for TA100, respectively. These results indicate that HU has a mutagenic potential at high concentrations above $234 \mu \mathrm{mol} / \mathrm{plate}$ using TA100 e TA102 Salmonella strain, although a previous study had showed the absence of mutagenicity of HU tested up $0.5 \mathrm{mg}$ per plate in TA100, TA98 and TA1537 [11]. There is no increase of HU mutagenicity in metabolic activation condition when compared with S9 absence (-S9) in prokaryotic cells. In eukaryotic cell, a study of HU, in mammalian (V79) cells, reported microsomal activation-dependent mutagenicity and found that the addition of catalase inhibited microsomemediated mutagenicity, indicating that hydrogen peroxide was involved in the formation of mutagenic DNA lesion [12].

In general, the mutagenicity of compounds 1-6 was observed mainly in the presence of metabolic activation (Table 1). The capacity to generate nitric oxide and/or radical species by nitrate ester seems to be dependent of the presence cystein residue. This condition occurs in the presence of metabolic activation $(+\mathrm{S} 9)$ and could be a possible explication for this event.

Compound 1 exhibited a mutagenic index of 2.4 in the TA100 strain in the absence of metabolic activation $(0.112 \mu \mathrm{mol} /$ plate $)$ and 2.3 in the TA102 strain in the presence of metabolic activation (0.056 $\mu \mathrm{mol} / \mathrm{plate})$. The mutagenic potency found was 1,795 revertants/ $\mu \mathrm{mol}$ and 4,803 revertants/ $\mu$ mol, respectively, for TA100 (-S9) and TA102 (+S9).

Compound 2 shows mutagenicity using strain TA100 at all the tested concentrations in the presence of metabolic activation. The higher value of the mutagenic index was 4.0 at $0.085 \mu \mathrm{mol} / \mathrm{plate}$. Mutagenicity was observed at $0.085 \mu \mathrm{mol} /$ plate in TA100 in the absence of metabolic activation (-S9). The mutagenic potency observed in TA100 was, respectively, 1,041 revertants/ $\mu \mathrm{mol}$ and 4,025 revertants/ $\mu \mathrm{mol}$ in the presence and absence of metabolic activation.

Compound 3 showed no mutagenicity at the used concentrations, although the test with TA102 strain in the presence of metabolic activation and the concentration of $3.58 \mu \mathrm{mol} / \mathrm{plate}$ provided a mutagenic index of 1.9 , showing signals of mutagenic activity.

Compound 4 only exhibited mutagenic activity at $15.7 \mu \mathrm{mol} /$ plate in the TA100 strain with metabolic activation $(\mathrm{MI}=2.7)$. The mutagenic potency observed in compound 4 in the presence of metabolic activation using TA100 was 13.6 revertants/ $\mu$ mol.

Compound 5 at $3.58 \mu \mathrm{mol} /$ plate showed in TA100 strain $(+\mathrm{S} 9)$ a mutagenic index of 2.0 and a mutagenic potency of 31 revertants/ $\mu$ mol, while in the absence of metabolic activation (-S9), at the same concentration it only showed evidence of mutagenicity $(\mathrm{MI}=1.9)$. The concentration of $1.8 \mu \mathrm{mol} / \mathrm{plate}$ in the absence of S9 in strain TA102, showed evidence of mutagenicity with MI equal to 1.9 . 
Compound 6, the phenyl-bridged derivative of compound 2, exhibited in the TA100 strain, in the presence of metabolic activation, mutagenic activity in all concentrations. The higher mutagenic index in a non toxic concentration was 5.8 at $2 \mu \mathrm{mol} /$ plate. The mutagenic potency observed in compound 6 using metabolic activation in TA100 was 1,393 revertants/ $\mu$ mol.

Compounds 1, 2, 3, 5 and $\mathbf{6}$ are phthalimide derivatives containing a nitrate ester subunit as NO-donor group. Several reports in the literature have demonstrated that NO induces mutagenesis using the Salmonella mutagenicity assay, specifically in tester strains that detect base-pair substitution mutations at the hisG46 mutation (e.g., TA100 and TA1535). Interestingly, NO was not mutagenic in TA102 and TA104 developed to detected oxidative mutagens at the base-pair substitution mutation hisG428 [13,14].

Compounds $\mathbf{1}$ and $\mathbf{2}$ are alkylphthalimide derivatives. Comparing compounds $\mathbf{1}$ and $\mathbf{2}$, we observed higher mutagenic index values in the latter. Table 2 shows that in TA100 strain (-S9) the mutagenic potency of compound 2 was 4,025 revertants/ $\mu$ mol, while compound 2 presented a mutagenic potency of 1,795 revertants/ $\mu$ mol.

Comparing compound $\mathbf{2}$ to compounds $\mathbf{3}$ and $\mathbf{5}$, it was observed that the former has higher mutagenic potency. The structural difference among these compounds is a substitution of methylene in compound $\mathbf{2}$ by a phenyl subunit present in compounds $\mathbf{3}$ and $\mathbf{5}$. These data lead us to suggest that the aryl derivatives, i.e., those which presented an aromatic ring linked to a phtalimide subunit (compounds $\mathbf{3}$ and $\mathbf{5}$ ), showed lower mutagenicity than alkyl derivatives.

Compound 4 is a sulfohydroxamic derivative (Table 1), which does not present the nitrate ester subunit, common to all compounds that presented mutagenic potency of 13.6 revertants/ $\mu \mathrm{mol}$. It is reported in the literature that hydroxylamine derivatives, or derivatives of hydroxamic acid present mutagenicity due to the capacity to generate radical species after oxidation [15-17]. The possible mutagenicity of the compound 4 , which occurs only in the presence of metabolic activation, could be attributed to the formation of an oxidized derivative or a radical compound. Comparing the concentration of the compound $\mathbf{4}$ used in the test to the aryl derivatives $(\mathbf{3}, \mathbf{5}$ and $\mathbf{6})$ it is observed that although mutagenic activity appears, this is only observed in high concentrations.

Comparing compound 5 to its regioisomer (compound 3), we observed a more discreet profile of mutagenicity of compound $\mathbf{5}$ in relation to the compound 3. This observation could be confirmed by data of mutagenic potency, while the compound 5 presented a potency of 31 revertant/ $\mu \mathrm{mol}$, the compound 3 did not present mutagenic activity.

Comparing compound $\mathbf{6}$ to compound 5, both with para- substitution, it is observed that the phenethyl spacer increases mutagenicity when compared to a benzyl spacer. This same fact is observed comparing compound $\mathbf{1}$ (methyl) and $\mathbf{2}$ (ethyl) and could be due to an adequate distance to form reactive species that interacts with DNA. This conclusion is based on NO-donor data that show no difference of NO release determining by Griess reaction between the compounds $\mathbf{1}$ and $\mathbf{2}$.

According to Table 2, the mutagenicity of all compounds is more accentuated with alkyl phthlimides derivatives than aryl phthalimides derivatives. TA100 detected mutagenic activity for compounds 2, 4, 5 and $\mathbf{6}$ whereas TA102 only detected mutagenic activity for compound $\mathbf{1 .}$

Although some compounds of this study presented a mutagenic index higher than 2 , it is important to note that drugs as metronidazole and nitrofurazone present mutagenic indexes higher than 14 [18]. 
So, other genotoxic studies using eukaryotic cells must be realized to investigate the capacity of the compounds 1-6 to cause genetic alterations.

\section{Experimental Section}

\subsection{Chemicals}

Hydroxyurea (HU, CAS No. 127-07-1), dimethylsulfoxide (DMSO, CAS No. 67-68-5), nicotinamide adenine dinucleotide phosphate sodium salt (CAS No. 11-84-16-3), D-glucose-6phosphate disodium salt (CAS No. 3671-99-6), magnesium chloride (CAS No. 7786-30-3), L-histidine monohydrate (CAS No. 7048-02-4), D-biotin (CAS No. 58-85-5), sodium azide (CAS No. 26628-228), 2-anthramine (CAS No. 613-13-8) and 2-aminofluorene (CAS No. 153-78-6) were purchased from Sigma Chemical Co. (St. Louis, MO, USA). Oxoid Nutrient Broth No. 2 (Oxoid, England) and Difco Bacto Agar (Difco, USA) were used as bacterial media. D-Glucose (CAS No. 154-17-6), magnesium sulfate (CAS No. 7487-88-9), citric acid monohydrate (CAS No. 5949-29-1), potassium phosphate dibasic anhydrous (CAS No. 7758-11-4), sodium ammonium phosphate (CAS No. 13011-54-6), sodium phosphate monobasic (CAS No. 7558-80-7), sodium phosphate dibasic (CAS No. 7558-79-4), sodium chloride (CAS No. 7647-14-5) were purchased from Merck (Whitehouse Station, NJ, USA).

\subsection{Preparation of Compounds 1-6}

The compounds were prepared through condensation of aminoalcohol derivatives with phthalic anhydride. The alcohol function of the phthalimide derivatives were converted to the final compounds containing nitrate ester functions [5]. Compound 4 was prepared by the previously described condensation of sulphonyl chloride [19] with hydroxylamine. The compounds 1-6 were characterized by ${ }^{1} \mathrm{H}$ - and ${ }^{13} \mathrm{C}-\mathrm{NMR}$, IR and MS. The purity was confirmed by elemental analysis and HPLC and in general was $99 \%$ for all compounds.

\subsection{Metabolic Activation System (S9 Mixture)}

The S9 fraction, prepared from livers of Sprague-Dawley rats treated with the polychlorinated biphenyl mixture Aroclor 1254, was purchased from Molecular Toxicology Inc. (Annapolis, MD, USA). The metabolic activation system consisted of $4 \%$ of $\mathrm{S} 9$ fraction, $1 \%$ of $0.4 \mathrm{M} \mathrm{MgCl}_{2}, 1 \%$ of 1.65 M KCl, $0.5 \%$ of $1 \mathrm{M}$ D-glucose-6-phosphate disodium and $4 \%$ of $0.1 \mathrm{M}$ b-nicotinamide adenine dinucleotide phosphate sodium in $0.1 \mathrm{M}, 50 \%$ of $0.2 \mathrm{M}$ phosphate buffer and $39.5 \%$ of sterile distilled water [20].

\subsection{Bacterial Strains}

TA100 and TA102 strains of Salmonella typhimurium were kindly supplied by Dr Bruce N. Ames from The University of California, Berkeley, USA. For all assays, an inoculum $(200 \mu \mathrm{L})$ of a thawed permanent culture was added to $20 \mathrm{~mL}$ of Oxoid Nutrient Broth No. 2 and incubated at $37{ }^{\circ} \mathrm{C}$ with shaking until a concentration of approximately $1-2 \times 10^{9}$ bacteria per milliliter was obtained. 


\subsection{Mutagenicity Assay}

The Salmonella mutagenicity assay was performed by pre-incubating the test compounds for 20-30 min with Salmonella typhimurium strains TA100 and TA102, with and without metabolic activation (S9 mixture) [21]. Compound 1 was tested at the following concentrations: 0.007; 0.014; $0.028 ; 0.056 ; 0.112 \mu \mathrm{mol}$ per plate. Compound 2 was used at $0.01 ; 0.021 ; 0.042 ; 0.085$ and $0.170 \mu \mathrm{mol}$ per plate. Compound 3 was used at $0.224 ; 0.488 ; 0.896 ; 1.8$ and $3.58 \mu \mathrm{mol}$ per plate. Compound 4 was used at $0.98 ; 1.96 ; 3.92 ; 7.85$ and $15.7 \mu$ mol per plate. Compound 5 was used at $0.244 ; 0.488 ; 0.896 ; 1.796$ and $3.584 \mu \mathrm{mol}$ per plate. Compound 6 was used at $0.12 ; 0.25 ; 0.5 ; 1.0$ and $2.0 \mu \mathrm{mol}$ per plate.

These doses were determined after the toxicity tests had been carried out. In all subsequent assays, the upper limit of the dose range tested was either the highest non-toxic dose or the lowest toxic dose determined in this preliminary assay. Toxicity was apparent either as a reduction in the number of his \pm revertants, or as an alteration in the auxotrophic background (i.e., background lawn).

The various concentrations of compounds to be tested were added to $500 \mu \mathrm{L}$ of buffer $\mathrm{pH} 7.4$ and $100 \mu \mathrm{L}$ of bacterial culture and then incubated at $37^{\circ} \mathrm{C}$ for $20-30 \mathrm{~min}$. After this time $2 \mathrm{~mL}$ of top agar was added to the mixture and poured on to a plate containing minimum agar. The plates were incubated at $37{ }^{\circ} \mathrm{C}$ for $48 \mathrm{~h}$ and the his \pm revertant colonies were manually counted. The influence of metabolic activation was tested by adding $500 \mu \mathrm{L}$ of $\mathrm{S} 9$ mixture (5\%). All experiments were performed in triplicate.

The standard mutagens used as positive controls in experiments without S9 mix were sodium azide $(1.25 \mu \mathrm{g} /$ plate) for TA100 and daunomycin ( $3 \mu \mathrm{g} / \mathrm{plate})$ for TA102. 2-Anthramine $(1.25 \mu \mathrm{g} / \mathrm{plate})$ was used with TA100 and 2-aminofluorene $(1.25 \mu \mathrm{g} /$ plate $)$ with TA102 in the experiments with metabolic activation. DMSO served as the negative (solvent) control $(100 \mu \mathrm{L} /$ plate).

The statistical analysis was performed with the Salanal computer program, adopting the Bernstein model [22]. The mutagenic index (MI) - the average number of revertants per plate divided by the average number of revertants per plate from the negative (solvent) control-was also calculated for each dose. A sample was considered positive when the MI was equal to or greater than 2 for at least one of the tested doses and if it had a reproducible dose-response curve [23,24].

\section{Conclusions}

Phthalimide derivatives with an ethyl spacer linked to a nitrate ester subunit contribute to generate compounds with higher mutagenic properties when compared with a methyl spacer. Furthermore, the introduction of nitrate ester subunit in the meta- aromatic position seems to decrease mutagenicity. The results indicate the structural requirement of phthalimide derivatives through mutagenic activity relationship study for the development of a new drug candidate to treat sickle cell disease symptoms' and allow us to characterize compound 3 as a new promising drug to treat this hematological disorder. 


\section{Acknowledgements}

These studies were supported by Coordenação de Aperfeiçoamento de Pessoal de Nível Superior (CAPES) and Fundação de Amparo à Pesquisa do Estado de São Paulo (FAPESP) ref. Process: 07/56115-0.

\section{References and Notes}

1. Steinberg, M.H. Sickle cell anemia, the first molecular disease: Overview of molecular etiology, pathophysiology and therapeutic approaches. ScientificWorldJournal 2008, 25, 1295-1324.

2. Raghupathy, R.; Billett, H.H. Promising therapies in sickle cell disease. Cardiovasc. Hematol. Dis. Drug Targets 2009, 9, 1-8.

3. Steinberg, M.H. Pathophysiologically based drug treatment of sickle cell disease. Trends Pharmacol. Sci. 2008, 27, 204-210.

4. Donehower, R.C. An overview of the clinical experience with hydroxyurea. Semin. Oncol. 1992, 19, 11-19.

5. Friedrisch, J.R.; Prá, D.; Maluf, S.W.; Bittar, C.M.; Mergener, M.; Pollo, T.; Kayser, M.; da Silva, M.A.; Henriques, J.A.; da Rocha Silla, L.M. DNA damage in blood leukocytes of individuals with sickle cell disease treated with hydroxyurea. Mutat. Res. 2008, 649, 213-220.

6. Santos, J.L.; Chung, M.C.; Lima, L.M.; Lanaro, C.; Costa, F.F. Use of Phthalimide and/or sulphonamide derivatives in the treatment of diseases which require reducing the TNF-alpha levels and exogenous source of nitric oxide, phthalimide derivatives, sulphonamide derivatives, and a method for obtaining a sulphonamide derivative. PCT Int Appl. WO2009073940, 2009.

7. Abu-Shakra, A. The mutagenic activity of the S-nitrosoglutathione/glutathione system in Salmonella typhimurium TA1535. Mutat. Res. 2003, 539, 203-206.

8. Donovan, P.J.; Smith, G.T.; Lawlor, T.E.; Cifone, M.A.; Murli, H.; Keefer, L.K. Quantification of diazeniumdiolate mutagenicity in four different in vitro assays. Nitric Oxide. 1997, 1, 158-166.

9. Arroyo, P.L.; Pigott, V.H.; Mower, H.F.; Cooney, R.V. Mutagenicity of nitric oxide and its inhibition by antioxidants. Mutat. Res. 1992, 281, 193-202.

10. $\mathrm{Xu}$, J.J. In vitro toxicology: Bringing the in silico and in vitro. Comput. Toxicol. 2007, 1, 21-32.

11. Bruce, W.R.; Heddle, J.A. The mutagenic activity of 61 agents as determined by the micronucleus, Salmonella and sperm abnormality assays. Can. J. Genet. Cytol. 1979, 21, 319-334.

12. Ziegler-Skilkakis, K.; Schwarz, L.R.; Andrae, U. Microsome- and hepatocyte-mediated mutagenicity of hydroxyurea and related aliphatic hydroxamic acids in V79 Chinese hamster cells. Mutat. Res. 1985, 152, 225-231.

13. Tamir, S.; Lewis, R.S.; Walker, T.R.; Deen, W.M.; Wishnok, J.S.; Tannenbaum, S.R. The influency of delivery rate on the chemistry and biological effects of nitric oxide. Chem. Res. Toxicol. 1993, 6, 895-899.

14. Saliim, E.T.; Abu-Shakra, A. Effect of hydrogen peroxide on nitric oxide (NO)-induced mutagenicity in Salmonella typhimurium. Teratog. Carcinog. Mutagen 2001, 21, 349-359.

15. Wei, C.I.; Cohen, M.D.; Swartz, D.D.; Fernando, S.Y.; Corbett, M.D. Mutagenicity of some monoaromatic hydroxamic acids. Toxicol. Lett. 1985, 24, 111-116. 
16. Wang, C.Y. Mutagenicity of hydroxamic acid for Salmonella typhimurium. Mutat. Res. 1977, 56, $7-12$.

17. Wang, C.Y.; Linsmaier-Bednar, E.M.; Lee, M.S.; King, C.M. Mutagenicities of $N$-acyl- $N$ arylhydroxylamines for Salmonella. Chem. Biol. Interact. 1988, 67, 215-223.

18. Bosquesi, P.L.; Almeida, A.E.; Blau, L.; Menegon, R.F.; Santos, J.L; Chung, M.C. Toxicity of nitrofuran drugs. J. Bas. Appl. Pharm. Sci. 2009, 29, 231-238.

19. Lima, L.M.; Castro, P.; Machado, A.L.; Fraga, C.A.M.; Lugnier, C.; Moraes, V.L.G.; Barreiro, E.J. Synthesis and anti-inflammatory activity of phthalimide derivatives, designed as new thalidomide analogs. Bioorg. Med. Chem. 2002, 10, 3067-3073.

20. Garner, R.C.; Miller, E.C.; Miller, J.A. Liver microsomal metabolism of aflatoxin B1 to a reactive derivative toxic to Salmonella typhimurium TA 1530. Cancer Res. 1972, 32, 2058-2066.

21. Maron, D.N.; Ames, B.N. Revised methods for the Salmonella mutagenicity test. Mutat. Res. 1983, 113, 173-215.

22. Bernstein, L.; Kaldor, J.; McCann, J.; Pike, M.C. An empirical approach to the statistical analysis of mutagenesis data from the Salmonella test. Mutat. Res. 1982, 97, 267-281.

23. Santos, F.V.; Colus, I.M.S.; Silva, M.A.; Vilegas, W.; Varanda, E.A. Assessment of DNA damage induced by extracts and fractions of Strychnos pseudoquina, a Brazilian medicinal plant with antiulcerogenic activity. Food Chem. Toxicol. 2006, 44, 1585-1589.

24. Varella, S.D.; Pozetti, G.L.; Vilegas, W.; Varanda, E.A. Mutagenic activity in waste from an aluminum products factory in Salmonella/microsome assay. Toxicol. Vitro 2004, 18, 895-900.

(C) 2010 by the authors; licensee Molecular Diversity Preservation International, Basel, Switzerland. This article is an open-access article distributed under the terms and conditions of the Creative Commons Attribution license (http://creativecommons.org/licenses/by/3.0/). 